\title{
Novedades jurídicas en Francia (2020-2021)
}

\author{
Laure Gisie \\ Doctoranda en Derecho Animal \\ Miembro del ICALP \\ Universitat Autònoma de Barcelona
}

Cita recomendada. GISIE, L., Novedades jurídicas en Francia (2020-2021), dA. Derecho Animal (Forum of Animal Law Studies) 12/2 (2021). - DOI https://doi.org/10.5565/rev/da.577

Resumen

La protección de los animales es tema de debate en la sociedad francesa. Esta crónica recoge los principales asuntos de actualidad legislativa y jurisprudencial en los primeros meses de 2021.

Palabras clave: animales; maltrato; abandono; proyecto de ley; tribunales; Francia.

Abstract - Legal developments in France (2020-2021)

The debate on the protection of animals is on the rise in the French society. This chronicle details the main current legislative and jurisprudential matters on animals in the first months of 2021.

Keywords: animals; mistreatment; abandonment; bill; courts; France.

\section{En Francia ¿hay avances para los animales?}

Durante los últimos diez años, la protección de los animales se ha convertido en un problema importante en nuestra sociedad. El barómetro anual "Los franceses y el bienestar de los animales" realizado por la Fundación 30 Millones de Amigos e Ifop ${ }^{1}$ reafirma que la protección de los animales es una de las principales preocupaciones de la sociedad.

En Francia, investigadores, asociaciones, ciudadanos e incluso funcionarios electos trabajan mano a mano para obtener una mayor protección de los animales. El Parti animaliste en Francia, incluso obtuvo sus primeros concejales municipales el pasado mes de junio ${ }^{2}$, lo que demuestra que la sucesión de escándalos que revelaron maltrato animal en Francia influyó en el voto de los ciudadanos.

En Montpellier, Eddine Ariztegui, comenzó su mandato como funcionario electo del Parti animaliste

1 Les Français et le bien-être des animaux Vague 4 (2021) - Sondage Ifop pour la Fondation 30 Millions d'Amis : https://www.ifop.com/wp-content/uploads/2021/01/IFOP117840-Présentation-30MA.pdf [Última consulta: 29 de abril de 2021]

2 Communiqué de Presse du Parti animaliste. Le Parti animaliste s'inscrit dans l'Histoire avec 12 conseillers municipaux (2020) : https://us14.campaign-archive.com/?u=4cf835b6972804cb746e68c19\&id=f010a6bb56 [Última consulta: 29 de abril de 2021] 
con fuerza, al iniciar en diciembre la rescisión de los acuerdos para la dotación de terrenos públicos para la actividad cinegética en todos los terrenos municipales. Los cazadores lo atacaron violentamente en las redes sociales. ${ }^{3}$

Los peces de la "Métropole de Grenoble" también podrán "respirar". Sandra Krief, funcionaria municipal, electa del Parti animaliste, pronunció un conmovedor discurso durante un concejo municipal, con el fin de instar a la "Métropole" (que representa un total de 49 ciudades) una fuerte oposición a la pesca viva ${ }^{4}$.

La pesca en vivo implica clavar un anzuelo en la espalda o en la boca de un animal, la mayoría de las veces un pez, para atraer a un depredador. Esta práctica cruel es controvertida, incluso entre los pescadores.

Alemania, Austria, Escocia, Irlanda y Suiza ya han prohibido esta práctica. "El INRA afirma que los cerebros de los peces tienen estructuras homólogas a las de los mamíferos que les permiten experimentar conscientemente el dolor y las emociones», subraya Sandra Krief. ${ }^{5}$

La "Métropole de Grenoble" votó a favor de este deseo.

Para los gatos, también se ha producido una gran mejora en la legislación francesa porque ahora se penaliza su no identificación. En Francia, cada año se abandonan entre 100.000 y 300.000 animales $^{6}$. Hay que tener en cuenta que el abandono se castiga con 2 años de prisión y una multa de $30.000 €$, pero hay muy pocos procesos porque es muy difícil caracterizar el delito. Francia mantiene más de 14 millones de gatos domésticos ${ }^{7}$. Entonces entiende la importancia de legislar para proteger a los animales.

Los artículos L212-10 8 y D212-63 del Código Rural ${ }^{9}$ prevén la identificación obligatoria de perros, gatos y carnívoros domésticos. Sin embargo, esta obligación venía acompañada de una sanción para el perro, pero no era el caso para el gato. Para armonizar y mejorar la ley, un nuevo decreto se ha aprobado en Francia el 18 de diciembre de $2020^{10}$. Desde este nuevo decreto, la no identificación de los gatos es sancionada con una multa de 750 euros.

Durante el mismo período, a finales de 2020, el tema del sufrimiento animal fue llevado a la Asamblea Nacional ${ }^{11}$. Pero después de algunos acalorados debates, se desestimó el proyecto de ley relativo a la mejora de las condiciones de vida de los animales y se pospondrá a una fecha posterior. Pero ¿para cuando? Los animales todavía tendrán que esperar.

Afortunadamente, a principios de 2021, se presentó un nuevo proyecto de ley ${ }^{12}$ destinado a fortalecer la lucha contra el maltrato animal y fue aprobado por la Asamblea Nacional en primera lectura, con algunas modificaciones al texto original. Ahora debe presentarse ante el Senado, pero hasta la fecha no se ha fijado un

3 Communiqué de Presse du Parti animaliste. Montpellier restreint le territoire des chasseurs : ceux-ci prennent violemment à partie l'élu animaliste sur les réseaux sociaux (2020):

https://us14.campaign-archive.com/?u=4cf835b6972804cb746e68c19\&id=79a12a1317 [Última consulta: 29 de abril de 2021]

4 Communiqué de Presse du Parti animaliste. Grenoble, une élue du Parti animaliste pionnière sur l'opposition à la pêche au vif. (2021) :

https://us14.campaign-archive.com/?u=4cf835b6972804cb746e68c19\&id=daf5c26a0a [Última consulta: 29 de abril de 2021] 5 Para ver el vídeo: https://twitter.com/Elus_PA/status/1357264400391036928

6 Regularmente se cita la cifra de 100.000 perros y gatos abandonados por año. Según los cálculos detallados en el Anexo 9 del Informe del Diputado Sr. Dombreval, esta cifra está subestimada. La estimación será que el total de animales potencialmente abandonados sea de 300.000. El bienestar de mascotas y equinos. (2020). [Última consulta: 29 de abril de 2021]

7 Número de gatos domésticos por país en Europa 2019. Publicado por Statista Research Department (2020): https://fr.statista.com/statistiques/531296/nombre-chats-par-pays-europe/\#: :text=La \% 20Francia\% $\quad 20$ comptait\% $20 \mathrm{en} \%$ 202019.5\% 20millones\% 20au\% 20Royaume\% 2DUni [Última consulta: 29 de abril de 2021]

8 Article L212-10. Modifié par LOI n²016-1087 du 8 août 2016 - art. 154. Les chiens et chats, préalablement à leur cession, à titre gratuit ou onéreux, sont identifiés par un procédé agréé par le ministre chargé de l'agriculture mis en œuvre par les personnes qu'il habilite à cet effet. Il en est de même, en dehors de toute cession, pour les chiens nés après le 6 janvier 1999 âgés de plus de quatre mois et pour les chats de plus de sept mois nés après le 1er janvier 2012. L'identification est à la charge du cédant. Dans les départements officiellement déclarés infectés de rage, l'identification est obligatoire pour tous les carnivores domestiques. https://www.legifrance.gouv.fr/codes/article_lc/LEGIARTI000033035507/

9 Article D212-63. Création Décret n²006-1662 du 21 décembre 2006 - art. 1. JORF 23 décembre 2006

"L'identification obligatoire des chiens, chats et carnivores domestiques prescrite à l'article L. 212-10 comporte, d'une part, le marquage de l'animal par tatouage ou tout autre procédé agréé par arrêté du ministre chargé de l'agriculture et, d'autre part, l'inscription sur le ou les fichiers prévus à l'article D. 212-66 des indications permettant d'identifier l'animal": https://www.legifrance.gouv.fr/codes/article_lc/LEGIARTI000006587862/

10 Décret ${ }^{\circ} 2020-1625$ du 18 décembre 2020 portant diverses mesures relatives au bien-être des animaux d'élevage et de compagnie : https://www.legifrance.gouv.fr/jorf/id/JORFTEXT000042702498 [Última consulta: 29 de abril de 2021]

11 Proposition de loi relative à de premières mesures d'interdiction de certaines pratiquesgénératrices de souffrances chez les animaux et d'amélioration des conditions de vie de ces derniers, N ${ }^{\circ} 3293$ : https://www.assembleenationale.fr/dyn/15/textes/115b3293_proposition-loi [Última consulta: 29 de abril de 2021]

12 Proposition de loi visant à renforcer la lutte contre la maltraitance animale, $\mathrm{N}^{\circ} 3661$ rectifié : https://www.assembleenationale.fr/dyn/15/textes/115b3661_proposition-loi [Última consulta: 29 de abril de 2021] 
calendario.

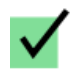

14 DÉCEMBRE 2020

Dépôt au parlement

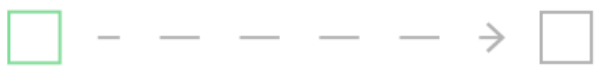

29 JANVIER 2021

\title{
Examen et adoption
}

\section{Promulgation}

\author{
1ère lecture
}

El proyecto de ley incluye diversas medidas para combatir el maltrato de animales domésticos y animales salvajes en cautiverio y mejorar sus condiciones de cautividad. Fue modificado por los diputados. De las 509 enmiendas presentadas durante la sesión plenaria, se aprobaron 64.

- Sobre las medidas:

El texto refuerza las sanciones contra el maltrato de animales domésticos. En efecto, el código penal francés actualmente castiga los malos tratos graves o los actos de crueldad hacia un animal doméstico pero la propuesta propone endurecer las sanciones:

- 3 años de prisión y multa de 45.000 euros en caso de maltrato grave

- 5 años de prisión y multa de 75.000 euros en caso de muerte del animal

Además, los tribunales podrán dictar en el futuro un curso de sensibilización sobre la prevención y la lucha contra el maltrato animal como pena alternativa o complementaria a la pena de prisión. Las decisiones de confiscar o prohibir la tenencia de un animal serán ingresadas en el archivo de personas buscadas. Se añaden nuevas disposiciones para reprimir la zoofilia y la zoopornografía en animales domésticos, domesticados o en cautiverio.

Con este proyecto de ley, para evitar el abandono de mascotas y limitar las compras impulsivas, se debe implementar un "certificado de compromiso y conocimiento" en el momento de la primera adquisición de un animal doméstico.

También para luchar contra el abandono, el texto propone generalizar la esterilización de gatos callejeros por parte de ayuntamientos o autoridades intermunicipales y refuerza la legislación sobre el traslado de nuevos animales de compañía (NAC).

Asimismo, cada municipio deberá disponer de una perrera o de un refugio apto para la recepción y la custodia, en condiciones que permitan garantizar su bienestar y su salud, de los perros y gatos que se encuentren vagabundos o en estado de vagabundeo.

El período de tenencia de animales en la perrera se amplía de 8 a 15 días, y cuando se identifica al animal, el administrador del refugio o la perrera debe buscar "lo antes posible" al dueño del animal.

La propuesta no sólo se ocupa de las mascotas, ya que parece ir hacia la prohibición de los animales salvajes en los circos ambulantes y delfinarios. En efecto, si se valida el texto, gradualmente se prohibirá la adquisición, posesión y reproducción para la exhibición de animales salvajes en circos ambulantes y delfinarios. Los espectáculos con animales salvajes también estarán prohibidos en discotecas o fiestas privadas y en televisión (programas de variedades, juegos, etc.).

Si la ley contra el maltrato animal presenta avances innegables, estos siguen siendo muy insuficientes y sólo atienden débilmente las demandas de la ciudadanía y el sufrimiento inaceptable que sufren los animales todos los días. Se han ignorado secciones enteras de la protección animal: la cría de animales, la matanza, las corridas de toros, la experimentación con animales, la caza, incluidas las cacerías tan difamadas, son temas que se pasan por alto.

A la espera de saber si el texto estará vigente, ha llegado una mala noticia para los denunciantes 
(whistleblower). La Ley de Seguridad Global se adoptó definitivamente en abril de $2021^{13}$. Su artículo 1 bis $A$ aumenta las penas por allanamiento de morada y prevé la represión y una mayor criminalización de los denunciantes que brinden información sobre cría intensiva en granjas. Las sanciones incurridas son una multa de $45.000 €$ y 3 años de prisión. Pero al final, el 20 de mayo de 2021, el Consejo Constitucional censuró esta disposición ${ }^{14}$.

Cabe señalar que el parlamento acaba de aprobar un proyecto de ley que introduce la noción de "patrimonio sensorial" del campo francés ${ }^{15}$. Esta ley se inspiró en el caso del gallo Maurice ${ }^{16}$, que fue el centro de un caso legal en Francia. Los vecinos se quejaron del cacareo matutino del gallo y finalmente los tribunales le permitieron seguir cacareando. El gallo se había convertido en un auténtico símbolo y era incluso conocido internacionalmente. A partir de ahora, el campo estará protegido y seguirá oliendo a campo y se podrá seguir escuchando a los animales, incluso muy temprano.

\section{En los tribunales, las cosas también se están moviendo}

Una decisión del "Conseil d’État" en Francia parece hablar por primera vez de un derecho a la vida de un perro ${ }^{17}$ :

CE 1 Dec. 2020, $n^{\circ}$ 446808; TA Paris, ord., 5 de noviembre de 2020, $n^{\circ} 2017962$.

Durante un control policial del dueño de un perro de raza "American Staff”, los oficiales de policía consideraron que el animal era un perro categorizado como "probablemente perro peligroso" de categoría 1, es decir un PPP. El problema, era que el propietario del perro no tenía licencia para mantener esta raza de perro y la policía decidió confiar el perro a una perrera.

La decisión de la Prefectura era de no devolver el perro y de pronunciar su sacrificio.

El "propietario" del perro presentó tres recursos paralelos ante el Tribunal Administrativo de París. Ha considerado que el decreto de la prefectura vulneraba su derecho a la defensa y, en particular, el derecho a beneficiarse de un peritaje morfológico contradictorio sobre el perro, su derecho a la propiedad y también el derecho a la vida del animal.

Esta acción legal llegó hasta un recurso ante el "Conseil d'État", lo que ha sido una oportunidad para pronunciarse sobre el derecho a la vida de un perro. Al aceptar, verificar de manera implícitamente, la violación del derecho a la vida del perro, el tribunal confirmó que este derecho existe.

Otra decisión, completamente diferente, condenó el matadero de Boischaut en Francia en abril de $2021^{18}$. Tras las impactantes imágenes desveladas en 2018 por la Asociación L214, el matadero había cerrado por completo durante 9 meses, y la actividad a tiempo completo no se reanudó hasta septiembre de 2020. Lo peor es que las no conformidades del matadero ya habían sido denunciadas en un informe de inspección veterinaria de $2016^{19}$. Eso era 2 años antes de la investigación de L214 y no se había tomado ninguna acción correctiva significativa.

Entre las infracciones, se observó que hubo falta de personal cualificado, que hubo un mal funcionamiento de la pinza eléctrica que supuestamente "aturde" a las ovejas y cabras, que hubo muchos fallos de encendido durante el aturdimiento por equipo de inmovilización inadecuado para los terneros, cabritos y corderos, y sobre todo un descontrol de la inconsciencia de los animales, que lleva al sacrificio y despiece de vacas aún vivas.

Pese a la gravedad de los hechos, hoy estos delitos constituyen a los ojos de la ley únicamente

13 Proposition de loi pour une sécurité globale préservant les libertés

http://www.senat.fr/petite-loi-ameli/2020-2021/495.html [Última consulta: 29 de abril de 2021]

14 Décision $\mathrm{n}^{\circ}$ 2021-817 DC du 20 mai 2021. Loi pour une sécurité globale préservant les libertés https://www.conseilconstitutionnel.fr/decision/2021/2021817DC.htm

15 Loi $\mathrm{n}^{\circ}$ 2021-85 du 29 janvier 2021 visant à définir et protéger le patrimoine sensoriel des campagnes françaises: https://www.legifrance.gouv.fr/jorf/id/JORFTEXT000043080343?r=1uhdlY5uwD [Última consulta: 29 de abril de 2021]

16 Artículo de prensa. Courrier international. Le Coq Maurice remporte « son procès » : un triomphe pour la campagne. (2019). Página web :

https://www.courrierinternational.com/article/vu-de-letranger-le-coq-maurice-remporte-son-proces-un-triomphe-pour-la-campagne [Última consulta: 29 de abril de 2021]

17 SOCHIRCA, N. «Le droit à la vie » d'un animal consacré par le juge administratif ? Dalloz Actualité (2021). Página web: https://www.dalloz-actualite.fr/node/droit-vie-d-un-animal-consacre-par-juge-administratif\#.YKKO5C2FBBw [Última consulta: 29 de abril de 2021]

18 Communiqué de presse. L214. Abattoir de Boischaut: https://www.1214.com/communications/20210407-jugement-abattoirboischaut [Última consulta: 29 de abril de 2021]

19 Ministère de l'agriculture et de l'alimentation. Abattoirs: La synthèse des audits (2016). Página web : https://agriculture.gouv.fr/abattoirs-la-synthese-des-audits [Última consulta: 29 de abril de 2021] 
infracciones, punibles con multa simple y el total de las multas pronunciadas por el Juzgado de Châteauroux ascendió a 86.000 euros.

\section{Referencias}

\section{Fuentes jurídicas}

- Article L212-10. Modifié par LOI n²016-1087 du 8 août 2016 - art. 154. https://www.legifrance.gouv.fr/codes/article_lc/LEGIARTI000033035507/

- Article D212-63. Création Décret n²006-1662 du 21 décembre 2006 - art. 1. JORF 23 décembre 2006. https://www.legifrance.gouv.fr/codes/article_lc/LEGIARTI000006587862/

- Décret $\mathrm{n}^{\circ}$ 2020-1625 du 18 décembre 2020 portant diverses mesures relatives au bien-être des animaux d'élevage et de compagnie:

- https://www.legifrance.gouv.fr/jorf/id/JORFTEXT000042702498 [Última consulta: 29 de abril de 2021]

- Décision n $\mathrm{n}^{\circ}$ 2021-817 DC du 20 mai 2021. Loi pour une sécurité globale préservant les libertés https://www.conseil-constitutionnel.fr/decision/2021/2021817DC.html

- Loi n ${ }^{\circ}$ 2021-85 du 29 janvier 2021 visant à définir et protéger le patrimoine sensoriel des campagnes françaises: $\quad$ https://www.legifrance.gouv.fr/jorf/id/JORFTEXT000043080343?r=1uhdlY5uwD [Última consulta: 29 de abril de 2021]

- Proposition de loi relative à de premières mesures d'interdiction de certaines pratiquesgénératrices de souffrances chez les animaux et d'amélioration des conditions de vie de ces derniers, $\mathrm{N}^{\circ} 3293$ : https://www.assemblee-nationale.fr/dyn/15/textes/115b3293_proposition-loi [Última consulta: 29 de abril de 2021]

- Proposition de loi visant à renforcer la lutte contre la maltraitance animale, $\mathrm{N}^{\circ} 3661$ rectifié : https://www.assemblee-nationale.fr/dyn/15/textes/115b3661_proposition-loi [Última consulta: 29 de abril de 2021]

- Proposition de loi pour une sécurité globale préservant les libertés.

- http://www.senat.fr/petite-loi-ameli/2020-2021/495.html [Última consulta: 29 de abril de 2021]

\section{Otras fuentes}

- Communiqué de presse. L214. Abattoir de Boischaut: https://www.1214.com/communications/20210407-jugement-abattoir-boischaut [Última consulta: 29 de abril de 2021]

- Communiqué de Presse du Parti animaliste. Le Parti animaliste s'inscrit dans l'Histoire avec 12 conseillers municipaux (2020): https://us14.campaignarchive.com/?u=4cf835b6972804cb746e68c19\&id=f010a6bb56 [Última consulta: 29 de abril de 2021]

- Communiqué de Presse du Parti animaliste. Montpellier restreint le territoire des chasseurs : ceuxci prennent violemment à partie l'élu animaliste sur les réseaux sociaux (2020) : https://us14.campaign-archive.com/?u=4cf835b6972804cb746e68c19\&id=79a12a1317 [Última consulta: 29 de abril de 2021]

- Communiqué de Presse du Parti animaliste. Grenoble, une élue du Parti animaliste

- pionnière sur l'opposition à la pêche au vif. (2021): https://us14.campaignarchive.com/?u=4cf835b6972804cb746e68c19\&id=daf5c26a0a [Última consulta: 29 de abril de 2021]

- Courrier international. Le Coq Maurice remporte «son procès» : un triomphe pour la campagne. (2019). Página web: https://www.courrierinternational.com/article/vu-de-letranger-le-coq-mauriceremporte-son-proces-un-triomphe-pour-la-campagne [Última consulta: 29 de abril de 2021]

- Les Français et le bien-être des animaux Vague 4 (2021) - Sondage Ifop pour la Fondation 30 Millions d'Amis: https:/www.ifop.com/wp-content/uploads/2021/01/IFOP117840-Présentation30MA.pdf [Última consulta: 29 de abril de 2021]

- Ministère de l'agriculture et de l'alimentation. Abattoirs : La synthèse des audits (2016). Página web: https://agriculture.gouv.fr/abattoirs-la-synthese-des-audits [Última consulta: 29 de abril de 2021] 
- SOCHIRCA, N. «Le droit à la vie» d'un animal consacré par le juge administratif ? Dalloz Actualité (2021). Página web: https://www.dalloz-actualite.fr/node/droit-vie-d-un-animal-consacre-par-jugeadministratif\#.YKKO5C2FBBw [Última consulta: 29 de abril de 2021]

- Statista Research Department (2020): https://fr.statista.com/statistiques/531296/nombre-chats-parpays-europe/\#: :text=La \% 20Francia\% 20comptait\% 20en\% 202019.5\% 20millones\% 20au\% 20Royaume\% 2DUni [Última consulta: 29 de abril de 2021]

- Vídeo: https://twitter.com/Elus_PA/status/1357264400391036928 